\title{
Differing effects of 2 active dried yeast (Saccharomyces cerevisiae) strains on ruminal acidosis and methane production in nonlactating dairy cows
}

\author{
Y.-H. Chung, ${ }^{\star}$ N. D. Walker, † S. M. McGinn, ${ }^{\star}$ and K. A. Beauchemin ${ }^{\star 1}$ \\ ${ }^{*}$ Agriculture and Agri-Food Canada, Research Center, Lethbridge, AB, T1J 4B1, Canada \\ †Lallemand Animal Nutrition, Montréal, QC, H4P 2T4, Canada
}

\begin{abstract}
Fifteen ruminally cannulated, nonlactating Holstein cows were used to measure the effects of 2 strains of Saccharomyces cerevisiae, fed as active dried yeasts, on ruminal $\mathrm{pH}$ and fermentation and enteric methane $\left(\mathrm{CH}_{4}\right)$ emissions. Nonlactating cows were blocked by total duration $(\mathrm{h})$ that their ruminal $\mathrm{pH}$ was below 5.8 during a 6-d pre-experimental period. Within each block, cows were randomly assigned to control (no yeast), yeast strain 1 (Levucell SC), or yeast strain 2 (a novel strain selected for enhanced in vitro fiber degradation), with both strains (Lallemand Animal Nutrition, Montréal, QC, Canada) providing $1 \times 10^{10}$ $\mathrm{cfu} /$ head per day. Cows were fed once daily a total mixed ration consisting of a 50:50 forage to concentrate ratio (dry matter basis). The yeast strains were dosed via the rumen cannula daily at the time of feeding. During the 35-d experiment, ruminal $\mathrm{pH}$ was measured continuously for $7 \mathrm{~d}$ (d 22 to 28 ) by using an indwelling system, and $\mathrm{CH}_{4}$ gas was measured for $4 \mathrm{~d}$ (d 32 to 35) using the sulfur hexafluoride tracer gas technique (with halters and yokes). Rumen contents were sampled on $2 \mathrm{~d}$ (d 22 and 26) at 0, 3, and $6 \mathrm{~h}$ after feeding. Dry matter intake, body weight, and apparent total-tract digestibility of nutrients were not affected by yeast feeding. Strain 2 decreased the average daily minimum ( 5.35 vs. 5.65 or 5.66 ), mean (5.98 vs. 6.24 or 6.34 ), and maximum ruminal $\mathrm{pH}$ (6.71 vs. 6.86 or 6.86 ), and prolonged the time that ruminal $\mathrm{pH}$ was below 5.8 ( 7.5 vs. 3.3 or $1.0 \mathrm{~h} / \mathrm{d}$ ) compared with the control or strain 1 , respectively. The molar percentage of acetate was lower and that of propionate was greater in the ruminal fluid of cows receiving strain 2 compared with cows receiving no yeast or strain 1. Enteric $\mathrm{CH}_{4}$ production adjusted for intake of dry matter or gross energy, however, did not differ between either yeast strain compared with the control but it tended to be reduced by $10 \%$ when strain 2 was compared with strain 1 . The study shows
\end{abstract}

Received March 19, 2010.

Accepted December 16, 2010.

${ }^{1}$ Corresponding author: karen.beauchemin@agr.gc.ca that different strains of S. cerevisiae fed as active dried yeasts vary in their ability to modify the rumen fermentative pattern in nonlactating dairy cows. Because strain 2 tended (when compared with strain 1) to lower $\mathrm{CH}_{4}$ emissions but increase the risk of acidosis, it may be prudent to further evaluate this strain in cattle fed high-forage diets, for which the risk of acidosis is low but $\mathrm{CH}_{4}$ emissions are high.

Key words: active dried yeast, ruminal acidosis, enteric methane emissions, sulfur hexafluoride tracer gas technique

\section{INTRODUCTION}

Yeast products based on Saccharomyces cerevisiae are increasingly used in ruminant diets to improve animal performance (Desnoyers et al., 2009; Robinson and Erasmus, 2009). Numerous commercial products are available and these vary widely in the strains of $S$. cerevisiae used and the number and viability of the yeast cells present. Host and dietary interactions may also alter the efficacy of some products. Consequently, animal responses to yeast supplementation of diets can be variable.

One potential mode of action of $S$. cerevisiae is to scavenge oxygen within the rumen creating a more anaerobic environment, which is required by ruminal microorganisms (Newbold et al., 1996). Saccharomyces cerevisiae is also thought to provide growth factors, including organic acids, B vitamins, and amino acids, that stimulate microbial growth in the rumen, thereby indirectly stabilizing ruminal $\mathrm{pH}$ (Chaucheyras-Durand et al., 2008). For example, Brossard et al. (2006) reported that yeast increased the protozoal population in the rumen of sheep, and Callaway and Martin (1997) showed that yeast stimulated the growth of 2 lactateutilizing bacteria, Selenomonas ruminantium and $\mathrm{Me}$ gasphaera elsdenii, in vitro. These authors suggested that the effects were due to the nutrients and (or) soluble growth factors provided to the ruminal microbes by the yeast. Williams et al. (1991) reported an elevated $\mathrm{pH}$ and a concurrent decreased concentration of lactate in the rumen of steers fed barley separate from hay and supplemented with yeast culture. Further studies 
have shown that certain strains of active dry yeast are particularly effective at raising and stabilizing ruminal $\mathrm{pH}$, even in diets that differ in their acidotic potential (Bach et al., 2007; Guedes et al., 2008). A less acidic and more anaerobic ruminal environment would help stimulate the growth of fiber-degrading microorganisms (Callaway and Martin, 1997) and could improve fiber degradation in the rumen (Williams et al., 1991).

Yeast also has the potential to alter the fermentation process in the rumen in a manner that reduces the formation of methane $\left(\mathrm{CH}_{4}\right)$ gas. Chaucheyras et al. (1995) reported a shift in $\mathrm{H}_{2}$ utilization from methanogenesis to reductive acetogenesis by yeast in vitro. Previously, McGinn et al. (2004) reported a $3 \%$ (g/ $\mathrm{kg}$ of DMI) decrease in in vivo $\mathrm{CH}_{4}$ production for one commercial yeast product, but a $6 \%$ increase for a second product. Newbold and Rode (2006) proposed that through strain selection, it may be possible to develop commercial yeast products that reduce $\mathrm{CH}_{4}$ output while minimizing ruminal acidosis and promoting ruminal fermentation and fiber digestion.

The objective of the experiment was to determine whether the risk of subacute ruminal acidosis (SARA) in dairy cows would be decreased by supplementing the diet with selected yeast strains based on $S$. cerevisiae. We also wanted to establish the variable effects of these yeast strains on ruminal fermentation, total-tract nutrient digestibility, and enteric $\mathrm{CH}_{4}$ emissions.

\section{MATERIALS AND METHODS}

\section{Experimental Design, Dietary Treatments, and Feeding of Cows}

The experiment was conducted as a randomized block design with 3 treatments and 5 replications per treatment. The experiment consisted of a 35-d yeast feeding period with ruminal $\mathrm{pH}$ measured continuously for $7 \mathrm{~d}$ (d 22 to 28) and $\mathrm{CH}_{4}$ gas collected daily for $4 \mathrm{~d}$ (d 32 to 35). Pre-experimental ruminal $\mathrm{pH}$ and $\mathrm{CH}_{4}$ emissions were measured for 6 and $4 \mathrm{~d}$, respectively, and the ruminal $\mathrm{pH}$ data obtained were used to block cows and assign them to treatment. Fifteen nonpregnant, nonlactating, and ruminally cannulated Holstein cows were assigned to 5 blocks by ranking the cows from high (more acidic) to low (less acidic) on the basis of their ruminal $\mathrm{pH}$. The ranking criterion was the total duration that ruminal $\mathrm{pH}$ was $<5.8$ during the 6 -d pre-experimental period $(18.1,10.5,4.2,1.4$, and $0 \mathrm{~h}$ per 6 -d period for block 1 to 5, respectively). Each block of cows had similar DMI (mean $\pm \mathrm{SD} ; 13.8 \mathrm{~kg} / \mathrm{d} \pm 2.7$ or $1.8 \%$ of $\mathrm{BW}$ $\pm 0.4 \mathrm{SD})$ and $\mathrm{BW}(771 \mathrm{~kg} \pm 158)$. A cow within each block was randomly assigned to (1) control (no yeast), (2) yeast strain 1 (Levucell SC), or (3) yeast strain
2 (a novel strain selected for enhanced in vitro fiber degradation; Walker et al., 2006; Chaucheyras-Durand et al., 2008). Both yeast strains were $S$. cerevisiae and were provided as active dried yeast (Lallemand Animal Nutrition, Montréal, QC, Canada) at $1 \times 10^{10} \mathrm{cfu} /$ head per day. Treatments were dosed via the rumen cannula daily at the time of feeding $(1 \times$ feeding/d $)$ to ensure each cow received the full amount.

Cows were fed a basal diet consisting of $50 \%$ barley silage, $19.5 \%$ steam-rolled barley grain, and $30.5 \%$ pellet supplement, which contained $11.95 \%$ canola meal, $8.5 \%$ cracked corn grain, $7.5 \%$ corn dry distillers grain with solubles, $1.75 \%$ trace minerals and vitamin supplement, $0.5 \%$ calcium carbonate, and $0.3 \%$ canola oil (dietary $\mathrm{DM}$ basis). The basal diet contained (mean $\pm \mathrm{SD}$ ): $51.6 \pm 4.2 \% \mathrm{DM}$ with an $\mathrm{OM}$ content of $92.0 \pm 0.3$, $\mathrm{CP}$ content of $16.9 \pm 0.6$, NDF content of $33.1 \pm 2.7$, ADF content of $20.0 \pm 1.4$, crude fat content of $3.4 \pm$ 0.4 , starch content of $28.4 \pm 1.3$ (\% of DM), and gross energy (GE) content of $4.3 \pm 0.05 \mathrm{Mcal} / \mathrm{kg}$ of dietary DM. The diet was formulated to meet the nutrient requirements of a dairy cow at $798 \mathrm{~kg}$ of $\mathrm{BW}$ producing $30 \mathrm{~kg} / \mathrm{d}$ of milk with $3.5 \%$ fat and $3.1 \%$ protein using the Cornell-Penn-Miner System (CPM Dairy, Version 3.0.8.01; Cornell University, Ithaca, NY; University of Pennsylvania, Kennett Square, PA; and William H. Miner Agricultural Research Institute, Chazy, NY). Although the diet exceeded the nutrient requirements of the nonlactating cows used in this study, a relatively high concentrate diet was used so that the effects of supplemental yeast on the risk of SARA could be evaluated.

Cows were fed for ad libitum intake (5\% refusal) once daily at $1300 \mathrm{~h}$. They were housed in a ventilated tiestall barn and had access to an open dry lot for exercise daily. Cows were handled and cared for using protocols approved by the Lethbridge Research Centre Animal Care Committee and in accordance with the guidelines of the Canadian Council on Animal Care (Ottawa, Ontario, Canada).

\section{Sample Collections and Measurements}

Feed Sampling and $\boldsymbol{B} \boldsymbol{W}$. Samples of the TMR and ingredients were collected weekly. The DM contents were determined immediately. Samples were composited and stored frozen until analyzed. Refusals were sampled daily from Monday to Friday, composited by week, and stored frozen until determinations of DM contents and chemical composition. The amount of feed offered and refused was recorded for each cow daily, and DMI was calculated using the DM content of the weekly TMR and refusal samples. Body weight of each cow was recorded once weekly. 
Ruminal $\boldsymbol{p H}$ and Fermentation. Ruminal $\mathrm{pH}$ was measured continuously every minute for $7 \mathrm{~d}$ using the Lethbridge Research Centre Ruminal pH Measurement System (LRCpH, Dascor, Escondido, CA) as described by Penner et al. (2006). The system was standardized at the start and end of the measurement period. A composite sample of rumen contents (500 g) was obtained from different sites within the rumen (dorsal and ventral sacs) at 0,3 , and $6 \mathrm{~h}$ after feeding on $2 \mathrm{~d}(\mathrm{~d} 22$ and 26). The rumen contents were squeezed through 2 layers of polyester monofilament fabric (Pecap 7-255/47, mesh opening of $355 \mu \mathrm{m}$, Tetko Inc., Scarborough, ON, Canada). A $5-\mathrm{mL}$ volume of the filtrate was mixed with $1 \mathrm{~mL}$ of $25 \%$ (wt/vol) $\mathrm{HPO}_{3}$ for VFA analysis, with $1 \mathrm{~mL}$ of $1 \%$ (wt/vol) $\mathrm{H}_{2} \mathrm{SO}_{4}$ for ammonia analysis, and with $1 \mathrm{~mL}$ of $1 \%$ (wt/vol) $\mathrm{H}_{2} \mathrm{SO}_{4}$ for lactic acid analysis. Samples were stored at $-20^{\circ} \mathrm{C}$ until analyzed. Another $5 \mathrm{~mL}$ of the filtrate was mixed with $10 \mathrm{~mL}$ of methyl green-formalin-saline solution for protozoa quantification. Samples were stored in a dark place at room temperature until analyzed.

Methane Gas Collection. Methane emissions were measured from individual cows for $4 \mathrm{~d}$ using the sulfur hexafluoride $\left(\mathbf{S F}_{\mathbf{6}}\right)$ tracer gas technique with halters and polyvinyl chloride yokes (Johnson et al., 1994) according to McGinn et al. (2009). The brass permeation tubes $(12.5 \mathrm{~mm} \times 40 \mathrm{~mm})$ used in this experiment contained on average (mean $\pm \mathrm{SD}$ ) $2,390 \mathrm{mg} \pm 46.8$ of ultrapure $\mathrm{SF}_{6}$. The release rates of $\mathrm{SF}_{6}$ from the permeation tubes ranged from 2.4 to $4.7 \mathrm{mg}$ of $\mathrm{SF}_{6} / \mathrm{d}$ with an average value of $3.5 \mathrm{mg}$ of $\mathrm{SF}_{6} / \mathrm{d} \pm 0.75 \mathrm{SD}$ and were similar between treatment groups. A halter was placed on the animal each day immediately before feeding. The yoke canister was placed on a shelf above the animal and was connected to the halter using an extension. Background levels of $\mathrm{SF}_{6}$ and $\mathrm{CH}_{4}$ were measured by suspending yokes in the barn. The yoke canister was removed after $22.5 \mathrm{~h}$ and sampled using a syringe.

Apparent Total-Tract Digestibility. Contents of indigestible NDF in feces, orts, and the basal experimental diet were used as internal markers for calculating apparent total-tract digestibility of nutrients (Cochran et al., 1986). From d 22 to 29 , fecal samples (100 \pm 5 g wet weight) were collected from the rectum of each cow at random times each day (twice daily; 15 samples per cow) to represent most of the hours in a 24-h period. The samples were pooled by cow, dried in a forced-air oven at $55^{\circ} \mathrm{C}$, and retained for measurements of analytical DM, OM, CP, NDF, ADF, and indigestible NDF.

\section{Laboratory Analyses}

Feed DM was determined immediately after collection by drying for $48 \mathrm{~h}$ at $55^{\circ} \mathrm{C}$ in a forced-air oven.
Samples of the composited TMR, ingredients, orts, and feces were oven-dried and ground in a Wiley mill (A. H. Thomas, Philadelphia, PA) through a 1-mm screen. Analytical DM content of the ground sample was determined by drying at $135^{\circ} \mathrm{C}$ for $2 \mathrm{~h}$ (method 930.15; AOAC, 2005), followed by hot weighing. The OM content was calculated as the difference between 100 and ash content (method 942.05; AOAC, 2005). The NDF and ADF contents were determined according to Van Soest et al. (1991) with heat-stable amylase and sodium sulfite used in the NDF procedure. The crude fat contents were determined using ether extraction (method 2003.05, AOAC, 2006; Extraction Unit E-816 HE, Büchi Labortechnik AG, Flawil, Switzerland). Gross energy content was determined using a bomb calorimeter (model E2k, CAL2k, Johannesburg, South Africa). The 1-mm ground samples were reground using a ball grinder (Mixer Mill MM2000, Retsch, Haan, Germany) for determination of $\mathrm{N}$ and starch. The $\mathrm{CP}(\mathrm{N} \times 6.25)$ content was determined by flash combustion with GC and thermal conductivity detection (Carlo Erba Instrumentals, Milan, Italy). Starch content was determined by enzymatic hydrolysis of $\alpha$-linked glucose polymers as described by Rode et al. (1999) with modifications. Tubes containing samples were initially incubated in a water bath at $90^{\circ} \mathrm{C}$ and vortexed at 10,20 , and 30 min of incubation without the use of activated carbon. Amyloglucosidase (200 $\mu \mathrm{L}$; Megazyme, Wicklow, Ireland) was added, tubes were vortexed immediately and twice subsequently at 30 and 60 min during $60^{\circ} \mathrm{C}$ incubation for $2 \mathrm{~h}$. Samples were centrifuged at 29,000 $\times g$ for $15 \mathrm{~min}$. Glucose Color Reagent was added $(300 \mu \mathrm{L}$; Diagnostic Chemicals, Charlottetown, PEI, Canada), and glucose was determined colorimetrically at $505 \mathrm{~nm}$ using a microtiter plate reader.

Ruminal VFA and lactic acid were quantified using GC (model 5890, Hewlett Packard, Wilmington, DE) with a capillary column $(30 \mathrm{~m} \times 0.32 \mathrm{~mm} \times 1 \mu \mathrm{m}$; ZB-FFAP, Phenomenex Inc., Torrance, CA) and flameionization detection. Internal standards were crotonic acid for the determination of VFA and malonic acid for lactic acid. For VFA, the oven temperature was $170^{\circ} \mathrm{C}$ for $4 \mathrm{~min}$, which was then increased by $3.5^{\circ} \mathrm{C} / \mathrm{min}$ to $180^{\circ} \mathrm{C}$ and then by $30^{\circ} \mathrm{C} / \mathrm{min}$ to $215^{\circ} \mathrm{C}$ and held at this temperature for $5 \mathrm{~min}$. For lactic acid, the oven temperature was $45^{\circ} \mathrm{C}$ for $1 \mathrm{~min}$, which was then increased by $30^{\circ} \mathrm{C} / \mathrm{min}$ to $150^{\circ} \mathrm{C}$ and then by $5^{\circ} \mathrm{C} / \mathrm{min}$ to $190^{\circ} \mathrm{C}$ and held at this temperature for $2.5 \mathrm{~min}$. The injector temperature was $225^{\circ} \mathrm{C}$, the detector temperature was $250^{\circ} \mathrm{C}$, and the carrier gas was helium. Samples for ruminal lactic acid were derivatized with boron trifluoride-methanol as described by Supelco (1998) before determination by GC. Rumen $\mathrm{NH}_{3}-\mathrm{N}$ concentration was determined by the salicylate-nitroprusside-hypochlorite 
method using a flow injection analyzer (Sims et al., 1995). Rumen protozoa were counted using a counting chamber (Neubauer Improved Bright-Line counting cell, $0.1 \mathrm{~mm}$ depth; Hausser Scientific, Horsham, PA) and a light microscope (Ogimoto and Imai, 1981). Duplicate preparations of each sample were counted and if either value differed from the average by more than $10 \%$, a third preparation of the sample was counted.

The concentrations of $\mathrm{SF}_{6}$ and $\mathrm{CH}_{4}$ in the gas samples taken from the yoke canisters were analyzed using GC (model 5890, Agilent Technologies, Santa Clara, CA) with flame-ionization detection (for $\left.\mathrm{CH}_{4}\right)$ and electron capture detection (for $\mathrm{SF}_{6}$ ). The columns (Alltech Associates, Deerfield, IL) used were Porapak $(1.8 \mathrm{~m} \times 0.3$ $\mathrm{cm})$ for $\mathrm{CH}_{4}$ and molecule sieve $(1.8 \mathrm{~m} \times 0.3 \mathrm{~cm} \times 0.2$ $\mathrm{cm})$ for $\mathrm{SF}_{6}$. Temperature for the oven was $35^{\circ} \mathrm{C}$, the injector was $170^{\circ} \mathrm{C}$, the flame-ionization detector and electron capture detector were both $250^{\circ} \mathrm{C}$, and the carrier gas was nitrogen. Standard curves for the GC were generated throughout the study using 5 gas standards between 18.3 and $299.5 \mathrm{nmol} / \mathrm{mol}$ for $\mathrm{SF}_{6}$ and between 1.6 and $250 \mu \mathrm{mol} / \mathrm{mol}$ for $\mathrm{CH}_{4}$. The correlation coefficient exceeded $99.9 \%$ for all standard curves.

Indigestible NDF contents were determined by incubating samples of feces, orts, and the diet (1-mm ground) in vitro for $120 \mathrm{~h}$ (DAISY ${ }^{\mathrm{II}}$ incubator; Ankom Technology, Macedon, NY), and NDF contents (with heat-stable amylase and sodium sulfite used in the procedure) of the samples were determined using the Ankom A200 Filter Bag Technique (Ankom Technology) after the 120 -h in vitro incubation.

\section{Statistical Analysis}

All variables, except for BW, apparent total-tract digestibility, and prevalence of long bouts of low ruminal $\mathrm{pH}$, were covariate-adjusted using pre-experimental measurements taken the same way as in the experimental period. Data were analyzed using PROC MIXED (SAS Institute, 1999) with the cow considered the experimental unit for all variables. For data that were collected serially (DMI, BW, $\mathrm{CH}_{4}$, and ruminal fermentation), the general linear mixed model included the fixed effect of treatment, sampling time, and their interaction, with sampling time considered a repeated effect (or double repeated effects for ruminal fermentation data) in the model. For data that were not collected serially (initial and final BW, change of BW, and digestibility of nutrients), the fixed effect of sampling time and its related interaction were removed from the general linear mixed model. Models also incorporated the pretrial period covariate when used. Denominator degrees of freedom were estimated using the Kenward-Roger option in the MODEL statement. Blocking factor and cow nested within treatment were used in the RANDOM statement. The PDIFF option adjusted by the Tukey method was included in the LSMEANS statement to account for multiple comparisons. Time-series covariance structure was modeled using the options of autoregressive order one, compound symmetry, unstructured, heterogeneous autoregressive order one, heterogeneous compound symmetry, and unstructured order one. The best time-series covariance structure was selected based on the lowest Akaike and Bayesian information criteria. Data for ruminal $\mathrm{pH}$ were summarized by day according to Dohme et al. (2008). The general linear mixed model for $\mathrm{pH}$ data included only the fixed effect of treatment. Day was used in the REPEATED statement with compound symmetry as the time-series covariance structure. Data are presented as least squares means \pm standard error of the means. Statistical significance was declared at $P \leq 0.05$ and a tendency to significance was declared at $0.05<P \leq 0.10$.

\section{RESULTS}

\section{Intake and BW}

Dry matter intake, as kilograms per day or a percentage of BW, fluctuated as the experiment progressed (week effect: $P<0.01$ ); however, these variables were not affected by yeast during the entire yeast feeding period (Table 1). Overall, average BW steadily increased from 804 to $823 \mathrm{~kg}$ ( \pm 4.3 pooled SEM; week effect: $P$ $<0.01$ ) during the experiment, but the average BW among treatments were similar. Each group started and ended the experiment with a similar initial and final $\mathrm{BW}$, respectively, and each gained similar weights by the end of the experiment.

\section{Ruminal Fermentation Characteristics}

Numbers of total protozoa and concentrations of lactate, ammonia-N, and total VFA in the rumen fluid were similar among treatments, but proportions of the major fermentation acids were different $(P \leq 0.05$; Table 2). Yeast strain 2 decreased $(P=0.04)$ the proportion of acetate in rumen fluid compared with yeast strain 1 and increased $(P<0.01)$ the proportion of propionate in ruminal fluid compared with the control or yeast strain 1 . As a result, yeast strain 2 decreased $(P \leq 0.01)$, when compared with yeast strain 1 , or tended $(P \leq 0.10)$ to decrease, when compared with the control, the ratios of acetate to propionate and lipogenic (acetate plus butyrate) to glucogenic (propionate) fermentation acids in the ruminal fluid. Yeast strain 2 also tended $(P=0.07)$ to increase the proportion of valerate. The ratio of acetate to propionate was 
Table 1. Dry matter intake and BW of nonlactating Holstein dairy cows fed a lactation diet supplemented with 2 strains of Saccharomyces cerevisiae as active dried yeasts

\begin{tabular}{|c|c|c|c|c|c|c|c|}
\hline \multirow[b]{2}{*}{ Variable } & \multicolumn{3}{|c|}{ Treatment } & \multirow[b]{2}{*}{ SEM } & \multicolumn{3}{|c|}{ Effect, $P$-value } \\
\hline & Control & Strain 1 & Strain 2 & & Treatment & Week & $\begin{array}{c}\text { Treatment } \\
\times \text { Week }\end{array}$ \\
\hline DMI, kg/d & 14.1 & 13.9 & 15.2 & 0.65 & 0.36 & $<0.01$ & 0.73 \\
\hline DMI, $\%$ of BW & 1.73 & 1.76 & 1.95 & 0.09 & 0.23 & $<0.01$ & 0.88 \\
\hline $\mathrm{BW}, \mathrm{kg}$ & 819 & 815 & 818 & 6.3 & 0.88 & $<0.01$ & 0.30 \\
\hline Initial BW, ${ }^{1} \mathrm{~kg}$ & 785 & 825 & 797 & 77.3 & 0.93 & - & - \\
\hline
\end{tabular}

${ }^{1}$ Initial and final BW and change of BW were not covariate adjusted.

the lowest (treatment $\times$ sampling hour interaction: $P=0.01)$ at $0 \mathrm{~h}$ before feeding for yeast strain 2 compared with control or yeast strain 1 . This low ratio of acetate to propionate was due to a lower proportion of acetate and a higher proportion of propionate at 0 $\mathrm{h}$ before feeding for cows fed diets supplemented with yeast strain 2 compared with cows fed control or yeast strain 1 (treatment $\times$ sampling hour interaction: $P$ $\leq 0.04)$. A tendency $(P=0.07)$ for a treatment $\times$ sampling time interaction was observed for lactic acid concentration and this interaction was due to yeast strain 1, which had a greater lactic acid concentration at $3 \mathrm{~h}$ after feeding compared with the control or yeast strain 2. However, lactic acid concentration at any sampling time point did not exceed $0.5 \mathrm{mM}$, which is considered to be very low.

\section{Ruminal pH Profile}

Ruminal $\mathrm{pH}$ profile was affected by strain of yeast (Table 3 ). Cows that received yeast strain 2 experi- enced lower $(P \leq 0.03)$ average daily minimum, mean, and maximum $\mathrm{pH}$ compared with cows that received no yeast or yeast strain 1 . Despite the lower $\mathrm{pH}$ profile of cows receiving yeast strain 2, the difference between average daily maximum and minimum $\mathrm{pH}$ was similar $(P=0.24)$ between treatment groups at 1.26 units $( \pm 0.3 \mathrm{SD})$. Cows receiving yeast strain 2 experienced a longer $(P<0.01)$ period of time that the ruminal $\mathrm{pH}$ was below 5.8 compared with cows receiving no yeast or yeast strain 1 . Cows receiving yeast strain 2 also had a more acidic ruminal environment, as indicated by a greater $(P<0.01)$ total area $(\mathrm{pH} \times$ min, calculated as area under the curve) that ruminal $\mathrm{pH}$ was below 5.8 compared with cows receiving no yeast or yeast strain 1. During a 24 -h period, cows receiving yeast strain 2 experienced more $(P=0.05)$ frequent bouts of ruminal $\mathrm{pH}<5.8$ compared with cows receiving yeast strain 1 . These bouts lasted longer $(P<0.01)$ for cows that received yeast strain 2 for $\mathrm{pH}<5.8$ compared with cows that received no yeast or yeast strain 1 . Prevalence of long bouts (bouts of $\mathrm{pH}<5.8$ for $>3 \mathrm{~h}$ ), expressed as

Table 2. Ruminal fermentation characteristics of nonlactating Holstein dairy cows fed a lactation diet supplemented with 2 strains of Saccharomyces cerevisiae as active dried yeasts

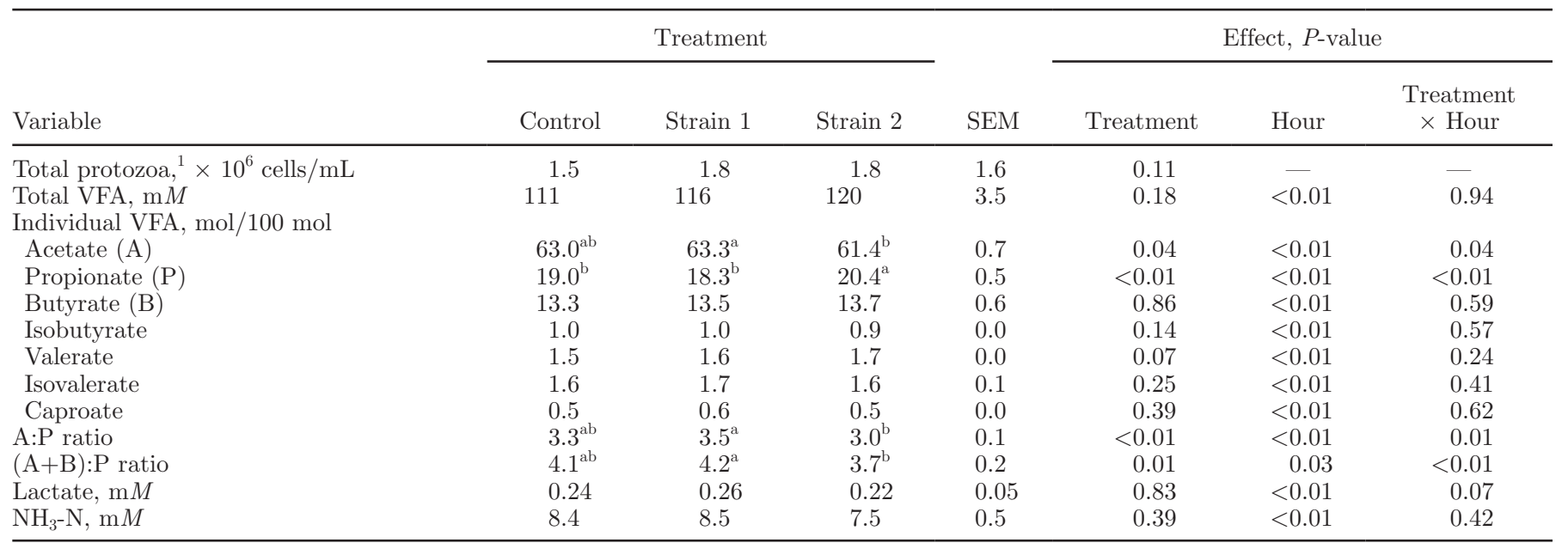

${ }^{\mathrm{a}, \mathrm{b}}$ Values within a row with different letters differ $(P \leq 0.06)$.

${ }^{1}$ Protozoa were counted only in samples taken at $3 \mathrm{~h}$ after feeding. 
Table 3. Ruminal pH profile of nonlactating Holstein dairy cows fed a lactation diet supplemented with 2 strains of Saccharomyces cerevisiae as active dried yeasts

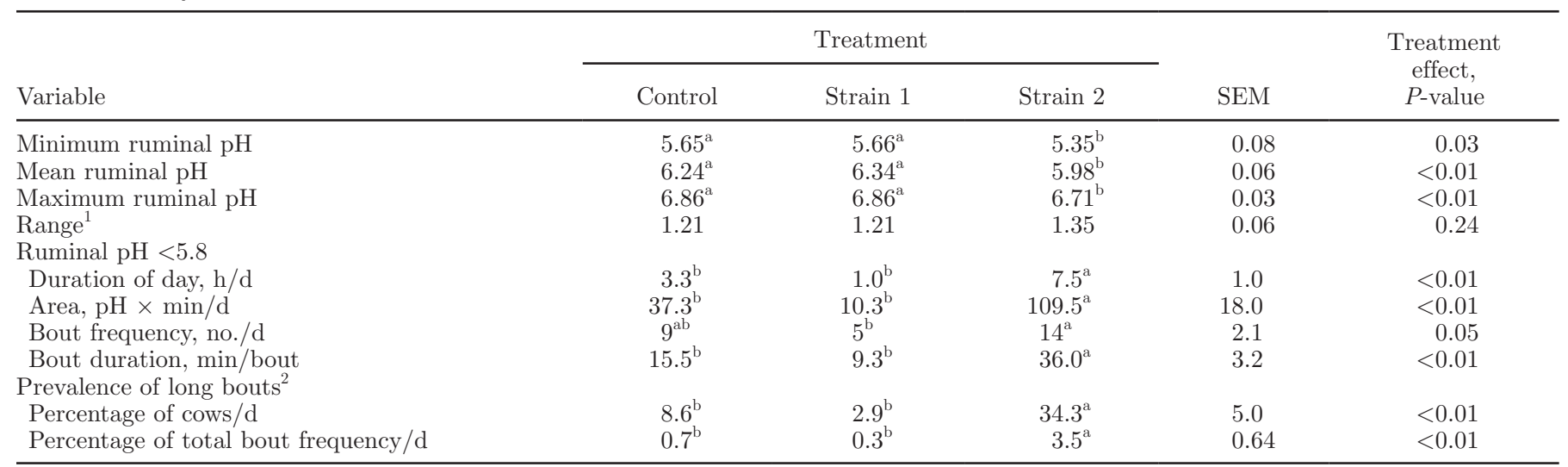

${ }^{\mathrm{a}, \mathrm{b}}$ Values within a row with different letters differ $(P \leq 0.05)$.

${ }^{1}$ Range $=$ maximum ruminal $\mathrm{pH}-$ minimum ruminal $\mathrm{pH}$.

${ }^{2} \mathrm{~A}$ long bout was defined as a bout at ruminal $\mathrm{pH}<5.8$ for $>3 \mathrm{~h}$. Prevalence of long bouts was expressed as the percentage of cows that had at least one long bout per day or as the percentage of total bout frequency per day. Prevalence of long bouts was not covariate adjusted.

a percentage of cows or as a percentage of daily total bouts, was the highest $(P<0.01)$ for yeast strain 2 -supplemented cows compared with the control or yeast strain 1-supplemented cows.

When the 24-h period was separated into three 8-h intervals, it was evident that the ruminal $\mathrm{pH}$ recordings decreased to their lowest point 8 to $16 \mathrm{~h}$ after feeding (Figure 1). Ruminal $\mathrm{pH}$ for cows receiving yeast strain 2 reached nadir $14.7 \mathrm{~h}$ after feeding compared with 10.5 or $10.6 \mathrm{~h}$ for cows receiving no yeast or yeast strain 1 , respectively, during a 24 -h period. Afterward, the $\mathrm{pH}$ recordings rebounded, and for cows fed the control or yeast strain 1 , the $\mathrm{pH}$ recordings 16 to $24 \mathrm{~h}$ after feeding were similar or even higher than in the period 0 to 8 $\mathrm{h}$ after feeding. In contrast, for cows fed yeast strain 2 , the low $\mathrm{pH}$ persisted 16 to $24 \mathrm{~h}$ after feeding, indicating that it took longer after feeding for $\mathrm{pH}$ to elevate when strain 2 was provided. Thus, cows fed yeast strain 2 were still experiencing some acidosis 16 to $24 \mathrm{~h}$ after feeding, which was not the case for cows fed the control or yeast strain 1 .

\section{Nutrient Digestibility and Enteric Methane Production}

No major effect of yeast feeding was observed for apparent total-tract digestibility of nutrients (DM, $\mathrm{OM}, \mathrm{CP}, \mathrm{NDF}$, and ADF) in this experiment (Table 4), except that apparent total-tract $\mathrm{CP}$ digestibility tended to be lower $(P=0.07)$ in cows receiving yeast strain 1.

Total enteric $\mathrm{CH}_{4}$ production expressed as grams per day was not affected by yeast feeding and averaged $264 \mathrm{~g} / \mathrm{d}$ (Table 5). However, enteric $\mathrm{CH}_{4}$ emission intensity, indicated as a ratio of grams of $\mathrm{CH}_{4} / \mathrm{kg}$ of DMI or a percentage of GE intake, tended (treatment effect: $P=0.07$ ) to be affected by yeast feeding. Yeast strain 2 tended to reduce $\mathrm{CH}_{4}$ emission intensity by $10 \%$ compared with strain $1(P=0.06)$; however, it did not reduce $\mathrm{CH}_{4}$ emission intensity compared with the control treatment. Yeast strain 1 also did not affect $\mathrm{CH}_{4}$ emission intensity compared with the control treatment.

Table 4. Apparent total-tract digestibility of nutrients for nonlactating Holstein dairy cows fed a lactation diet supplemented with 2 strains of Saccharomyces cerevisiae as active dried yeasts

\begin{tabular}{|c|c|c|c|c|c|}
\hline \multirow[b]{2}{*}{ Variable } & \multicolumn{3}{|c|}{ Treatment } & \multirow[b]{2}{*}{ SEM } & \multirow{2}{*}{$\begin{array}{c}\text { Treatment } \\
\text { effect, } \\
P \text {-value }\end{array}$} \\
\hline & Control & Strain 1 & Strain 2 & & \\
\hline $\mathrm{DM}, \%$ & 62.9 & 61.7 & 61.2 & 0.74 & 0.14 \\
\hline $\mathrm{OM}, \%$ & 63.8 & 62.7 & 62.1 & 0.71 & 0.16 \\
\hline $\mathrm{CP}, \%$ & $63.6^{\mathrm{a}}$ & $61.2^{\mathrm{b}}$ & $62.4^{\mathrm{ab}}$ & 0.75 & 0.07 \\
\hline NDF, $\%$ & 40.0 & 38.3 & 37.7 & 1.07 & 0.25 \\
\hline $\mathrm{ADF}, \%$ & 24.6 & 24.1 & 23.4 & 1.58 & 0.76 \\
\hline Digestible DMI, $\mathrm{kg} / \mathrm{d}$ & 9.0 & 8.5 & 9.0 & 0.48 & 0.74 \\
\hline
\end{tabular}

${ }^{a, b}$ Values within a row with different letters differ $(P \leq 0.06)$. 
Dry matter intake decreased (week effect: $P<0.01$ ) from $17.0 \mathrm{~kg} / \mathrm{d}$ on d 1 to $14.8 \mathrm{~kg} / \mathrm{d}$ on d 4 of $\mathrm{CH}_{4}$ collection, indicating that the cows may have been stressed by the procedure, which included daily handling and wearing a halter. A treatment $\times$ sampling day interaction $(P=0.02)$ occurred for DMI during $\mathrm{CH}_{4}$ collection. This interaction reflected the daily fluctuation in DMI within each treatment group, but no effect of treatment on daily DMI was evident.

\section{DISCUSSION}

The study demonstrates that strains of $S$. cerevisiae differ in their effects on ruminal fermentation, an effect previously reported in vitro (Chaucheyras-Durand et al., 2008). Yeast strain 1 is a commercial product widely used in dairy production that has been shown to enhance animal performance, specifically fat-corrected milk production and feed conversion efficiency, especially during the early part of lactation (de Ondarza et al., 2010). An increase in ruminal pH previously reported for this yeast strain (Bach et al., 2007) is likely to contribute in part to any improvement in animal performance by yeast strain 1 . Under the dietary conditions of our study, however, yeast strain 1 had no major effects on any of the measurements taken in this study, although time spent below a $\mathrm{pH}$ detrimental to fiber degradation ( $\mathrm{pH}<5.8)$ was numerically reduced by yeast strain 1. A relatively higher degree of variability in the $\mathrm{pH}$ data, specifically the duration, severity, and bouts (both frequency and duration) of SARA, may have prevented a difference between the yeast strain 1 and control.

Yeast strain 2 is a novel strain that is not used commercially but that has been observed to increase the rate of fiber digestion and ammonia utilization in vitro with mixed rumen contents (Walker et al., 2006; Chaucheyras-Durand et al., 2008). In our study, however, yeast strain 2 had no effects on ammonia concentration in the rumen. We did not examine whether yeast strain 2 enhanced the rate of fiber digestion in the rumen, but ruminal fermentation appeared to be increased by yeast strain 2 toward a more glucogenic fermentative pattern. The more glucogenic fermentative pattern observed for cows receiving yeast strain 2 could be an indication of a shift in species composition within the microbial populations. Similar to our study, Harrison et al. (1988) reported that feeding yeast culture stimulated the proportion of propionate at the expense of acetate proportion, and in their study there was a concurrent increase in the number of total anaerobic and cellulolytic bacteria in the rumen.

Yeast strain 2 had no effects on apparent total-tract digestibility of dietary nutrients, whereas yeast strain 1

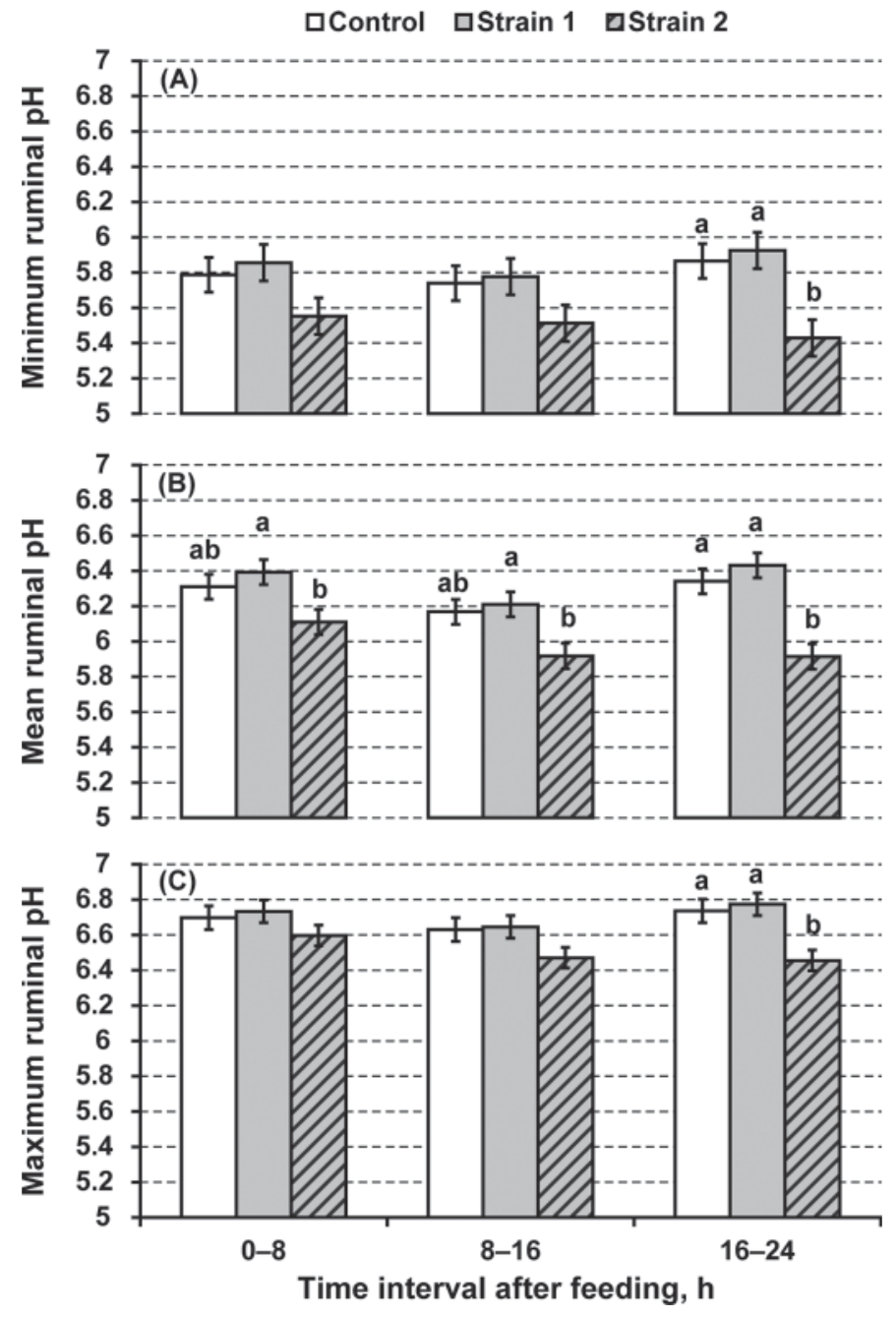

Figure 1. Minimal (A), mean (B), and maximum (C) ruminal $\mathrm{pH}$ by 8 -h time intervals relative to feeding during a 24 -h period for nonlactating Holstein dairy cows fed a lactation diet supplemented with 2 strains of Saccharomyces cerevisiae as active dried yeasts. ${ }^{\text {ab }} P \leq 0.05$. (A) Treatment: $P=0.02$; time interval: $P=0.17$; treatment $\times$ time interval: $P<0.01$. (B) Treatment: $P<0.01$; time interval: $P<0.01$; treatment $\times$ time interval: $P<0.01$. (C) Treatment: $P<0.01$; time interval: $P=0.18$; treatment $\times$ time interval: $P=0.02$.

tended to reduce the apparent total-tract digestibility of dietary CP by $4 \%$. Because the mode of action of yeast is primarily to alter ruminal fermentation, it is possible for total-tract digestibility not to be affected. Compensatory postruminal digestion can mask the effects of yeast on ruminal digestion of nutrients (Yoon and Stern, 1996). For example, Yoon and Stern (1996) reported that ruminal digestion of $\mathrm{OM}$ and $\mathrm{CP}$ was improved by providing cows with yeast culture, but apparent total-tract digestion of $\mathrm{OM}$ and $\mathrm{CP}$ were similar for control versus yeast culture-supplemented cows. Dietary factors (e.g., dietary levels of concentrate and NDF) may also influence the effect of yeast on totaltract digestibility of nutrients (Desnoyers et al., 2009). 
Table 5. Methane emissions from nonlactating Holstein dairy cows fed a lactation diet supplemented with 2 strains of Saccharomyces cerevisiae as active dried yeasts

\begin{tabular}{|c|c|c|c|c|c|c|c|}
\hline \multirow[b]{2}{*}{ Variable } & \multicolumn{3}{|c|}{ Treatment } & \multirow[b]{2}{*}{ SEM } & \multicolumn{3}{|c|}{ Effect, $P$-value } \\
\hline & Control & Strain 1 & Strain 2 & & Treatment & Day & $\begin{array}{c}\text { Treatment } \\
\times \text { Day }\end{array}$ \\
\hline DMI during $\mathrm{CH}_{4}$ collection, $\mathrm{kg} / \mathrm{d}$ & 16.1 & 15.1 & 16.7 & 0.6 & 0.20 & $<0.01$ & 0.02 \\
\hline \multicolumn{8}{|l|}{ Methane emission intensity } \\
\hline Ratio, $\mathrm{g}$ of $\mathrm{CH}_{4} / \mathrm{kg}$ of DMI & $16.9^{\mathrm{ab}}$ & $17.5^{\mathrm{a}}$ & $15.7^{\mathrm{b}}$ & 0.6 & 0.07 & 0.06 & 0.19 \\
\hline
\end{tabular}

${ }^{\mathrm{a}, \mathrm{b}}$ Values within a row with different letters differ $(P \leq 0.06)$.

The increased rumen acidity observed in cows receiving yeast strain 2 was likely driven by a more rapid accumulation of VFA in the rumen (Erfle et al., 1982; Nagaraja and Titgemeyer, 2007). The main difference between the ruminal $\mathrm{pH}$ profiles in cows supplemented with yeast strain 2 and those in control cows or cows receiving yeast strain 1 was the more frequent occurrence of long bouts of low $\mathrm{pH}$ (ruminal $\mathrm{pH}$ at $<5.8$ for $>3 \mathrm{~h}$ /bout). Gozho et al. (2005) defined SARA as daily episodes of ruminal $\mathrm{pH}$ at $<5.6$ for $\geq 3 \mathrm{~h} / \mathrm{d}$, because this threshold for ruminal $\mathrm{pH}$ elicited an inflammatory response in steers with grain-induced SARA. Based on this criterion of bouts of low $\mathrm{pH}$, cows receiving yeast strain 2 experienced more SARA. However, the greater extent of SARA for cows fed yeast strain 2 had minimal negative effects on other variables, such as ruminal concentrations of lactate, numbers of protozoa in the rumen, BW change, DMI, or total-tract digestibility of DM or NDF. More research is needed to evaluate the effect of yeast strain 2 on animal performance and SARA in lactating cows with a higher level of feed intake and fed different types of diets. Methods of delivery of the yeast also need to be evaluated; for example, slow-releasing under normal feeding regimen versus pulse-dosing, as in this study.

The present study shows that different strains of $S$. cerevisiae vary in their ability to mitigate enteric $\mathrm{CH}_{4}$ emissions. The ability of yeast strain 2 to modify the rumen toward a more glucogenic and more acidic environment would have created less favorable conditions for methanogenesis. Production of propionate serves as a competitive pathway for $\mathrm{H}_{2}$ in the rumen (Boadi et al., 2004); thus, the lower acetate to propionate ratio in the rumen of cows fed yeast strain 2 indicates a lower potential for $\mathrm{CH}_{4}$ production. Low $\mathrm{pH}$ inhibits $\mathrm{CH}_{4}$ production in vitro (Van Kessel and Russell, 1996; Russell, 1998) because of detrimental effects of low $\mathrm{pH}$ on methanogens and protozoa (Jones et al., 1987; Nagaraja and Titgemeyer, 2007). However, in the present study, the low $\mathrm{pH}$ induced by yeast strain 2 had no effects on the protozoal population in the rumen.
Yeast strain 1 was shown in vitro to shift $\mathrm{H}_{2}$ utilization from methanogenesis to reductive acetogenesis (Chaucheyras et al., 1995). However, a previous in vivo study (McGinn et al., 2004) and the current study do not support this observation for this particular strain of yeast. McGinn et al. (2004) reported no reductions in in vivo $\mathrm{CH}_{4}$ production (as $\mathrm{g}$ of $\mathrm{CH}_{4}$ per $\mathrm{kg}$ of DMI or as a percentage of GE intake) by supplementing cattle fed a high-forage diet with a yeast product containing yeast strain 1 . In the current study, yeast strain 1 did not decrease $\mathrm{CH}_{4}$ production (as $\mathrm{g}$ of $\mathrm{CH}_{4}$ per $\mathrm{kg}$ of DMI or as a percentage of GE intake) compared with the control. Differing effects of yeast on enteric $\mathrm{CH}_{4}$ production, as was observed for strain 1 versus strain 2 in this study, indicates strain-dependent effects of yeasts on ruminal fermentation (Newbold et al., 1995).

\section{CONCLUSIONS}

Yeast strain 1 had no major effects under these dietary conditions on any of the measurements taken in this study. In contrast, yeast strain 2 modified ruminal fermentation toward a more glucogenic pattern and resulted in more SARA. Yeast strain 2, however, did not reduce enteric $\mathrm{CH}_{4}$ emissions when compared with the control but it tended to reduce enteric $\mathrm{CH}_{4}$ production adjusted for intake of DM or GE by $10 \%$ when compared with strain 1 . Because strain 2 tended (when compared with strain 1) to lower $\mathrm{CH}_{4}$ emissions but increased the risk of acidosis, it may be prudent to further evaluate this strain in cattle fed high-forage diets, for which the risk of acidosis is low, but $\mathrm{CH}_{4}$ emissions are high.

\section{ACKNOWLEDGMENTS}

The authors thank (all of Agriculture and AgriFood Canada, Lethbridge) K. Andrews, B. Farr, and L. Holtshausen for sampling and laboratory analysis, T. Coates for assisting with the $\mathrm{CH}_{4}$ measurement, D. Vedres for gas analysis, and the staff at the Metabolism 
Unit of the Lethbridge Research Centre (Lethbridge, AB, Canada) for animal care. Funding for the study was from Lallemand Animal Nutrition (Montréal, QC, Canada), the Alberta Livestock Industry Development Fund, and Agriculture and Agri-Food Canada.

\section{REFERENCES}

AOAC. 2005. Official Methods of Analysis. 18th ed. AOAC Int., Gaithersburg, MD.

AOAC. 2006. Official Methods of Analysis. Revision 1. 18th ed. AOAC Int., Gaithersburg, MD.

Bach, A., C. Iglesias, and M. Devant. 2007. Daily rumen pH pattern of loose-housed dairy cattle as affected by feeding pattern and live yeast supplementation. Anim. Feed Sci. Technol. 136:146-153.

Boadi, D., C. Benchaar, J. Chiquette, and D. Massé. 2004. Mitigation strategies to reduce enteric methane emissions from dairy cows: Update review. Can. J. Anim. Sci. 84:319-335.

Brossard, L., F. Chaucheyras-Durand, B. Michalet-Doreau, and C. Martin. 2006. Dose effect of live yeasts on rumen microbial communities and fermentations during butyric latent acidosis in sheep: New type of interaction. Anim. Sci. 82:829-836.

Callaway, E. S., and S. A. Martin. 1997. Effects of a Saccharomyces cerevisiae culture on ruminal bacteria that utilize lactate and digest cellulose. J. Dairy Sci. 80:2035-2044.

Chaucheyras, F., G. Fonty, G. Bertin, and P. Gouet. 1995. In vitro $\mathrm{H}_{2}$ utilization by a ruminal acetogenic bacterium cultivated alone or in association with an archaea methanogen is stimulated by a probiotic strain of Saccharomyces cerevisiae. Appl. Environ. Microbiol. 61:3466-3467.

Chaucheyras-Durand, F., N. D. Walker, and A. Bach. 2008. Effects of active dry yeasts on the rumen microbial ecosystem: Past, present and future. Anim. Feed Sci. Technol. 145:5-26.

Cochran, R. C., D. C. Adams, J. D. Wallace, and M. L. Galyean. 1986. Predicting digestibility of different diets with internal markers: Evaluation of four potential markers. J. Anim. Sci. 63:14761483.

de Ondarza, M. B., C. J. Sniffen, L. Dussert, E. Chevaux, J. Sullivan, and N. Walker. 2010. Case study: Multiple study analysis of the effect of live yeast on milk yield, milk component content and yield, and feed efficiency. Prof. Anim. Sci. 26:661-666.

Desnoyers, M., S. Giger-Reverdin, G. Bertin, C. Duvaux-Ponter, and D. Sauvant. 2009. Meta-analysis of the influence of Saccharomyces cerevisiae supplementation on ruminal parameters and milk production of ruminants. J. Dairy Sci. 92:1620-1632.

Dohme, F., T. J. DeVries, and K. A. Beauchemin. 2008. Repeated ruminal acidosis challenges in lactating dairy cows at high and low risk for developing acidosis: Ruminal pH. J. Dairy Sci. 91:35543567.

Erfle, J. D., R. J. Boila, R. M. Teather, S. Mahadevan, and F. D. Sauer. 1982. Effect of $\mathrm{pH}$ on fermentation characteristics and protein degradation by rumen microorganisms in vitro. J. Dairy Sci. 65:1457-1464.

Gozho, G. N., J. C. Plaizier, D. O. Krause, A. D. Kennedy, and K. M. Wittenberg. 2005. Subacute ruminal acidosis induces ruminal lipopolysaccharide endotoxin release and triggers an inflammatory response. J. Dairy Sci. 88:1399-1403.

Guedes, C. M., D. Gonçalves, M. A. M. Rodrigues, and A. Dias-daSilva. 2008. Effects of a Saccharomyces cerevisiae yeast on ruminal fermentation and fibre degradation of maize silages in cows. Anim. Feed Sci. Technol. 145:27-40.

Harrison, G. A., R. W. Hemken, K. A. Dawson, R. J. Harmon, and K. B. Barker. 1988. Influence of addition of yeast culture supplement to diets of lactating cows on ruminal fermentation and microbial populations. J. Dairy Sci. 71:2967-2975.

Johnson, K. A., M. Huyler, H. Westberg, B. Lamb, and P. Zimmerman. 1994. Measurement of methane emissions from ruminant livestock using a sulfur hexafluoride tracer technique. Environ. Sci. Technol. 28:359-362.

Jones, W. J., D. P. Nagle Jr., and W. B. Whitman. 1987. Methanogens and the diversity of archaebacteria. Microbiol. Rev. 51:135-177.

McGinn, S. M., K. A. Beauchemin, T. Coates, and D. Colombatto. 2004. Methane emissions from beef cattle: Effects of monensin, sunflower oil, enzymes, yeast, and fumaric acid. J. Anim. Sci. 82:3346-3356.

McGinn, S. M., Y.-H. Chung, K. A. Beauchemin, A. D. Iwaasa, and C. Grainger. 2009. Use of corn distillers dried grains to reduce enteric methane loss from beef cattle. Can. J. Anim. Sci. 89:409-413.

Nagaraja, T. G., and E. C. Titgemeyer. 2007. Ruminal acidosis in beef cattle: The current microbiological and nutritional outlook. J. Dairy Sci. 90(E. Suppl.):E17-E38.

Newbold, C. J., and L. M. Rode. 2006. Dietary additives to control methanogenesis in the rumen. Pages 138-147 in Greenhouse Gases and Animal Agriculture: An Update. Elsevier, Amsterdam, the Netherlands.

Newbold, C. J., R. J. Wallace, X. B. Chen, and F. M. Mcintosh. 1995. Different strains of Saccharomyces cerevisiae differ in their effects on ruminal bacterial numbers in vitro and in sheep. J. Anim. Sci. $73: 1811-1818$.

Newbold, C. J., R. J. Wallace, and F. M. Mcintosh. 1996. Mode of action of the yeast Saccharomyces cerevisiae as a feed additive for ruminants. Br. J. Nutr. 76:249-261.

Ogimoto, K., and S. Imai. 1981. Page 158 in Atlas of Rumen Microbiology. Japan Sci. Soc. Press, Tokyo, Japan.

Penner, G. B., K. A. Beauchemin, and T. Mutsvangwa. 2006. An evaluation of the accuracy and precision of a stand-alone submersible continuous ruminal pH measurement system. J. Dairy Sci. 89:2132-2140.

Robinson, P. H., and L. J. Erasmus. 2009. Effects of analyzable diet components on responses of lactating dairy cows to Saccharomyces cerevisiae based yeast products: A systematic review of the literature. Anim. Feed Sci. Technol. 149:185-198.

Rode, L. M., W. Z. Yang, and K. A. Beauchemin. 1999. Fibrolytic enzyme supplements for dairy cows in early lactation. J. Dairy Sci. 82:2121-2126.

Russell, J. B. 1998. The importance of $\mathrm{pH}$ in the regulation of ruminal acetate to propionate ratio and methane production in vitro. J. Dairy Sci. 81:3222-3230.

SAS Institute. 1999. SAS/STAT User's Guide: Statistics. Version 8 ed. SAS Inst. Inc., Cary, NC.

Sims, G. K., T. R. Ellsworth, and R. L. Mulvaney. 1995. Microscale determination of inorganic nitrogen in water and soil extracts. Commun. Soil Sci. Plant Anal. 26:303-316.

Supelco. 1998. Analyzing fatty acids by packed column gas chromatography. Pages 5-7 In Bulletin 856. Sigma-Aldrich Corp., Bellefonte, PA.

Van Kessel, J. S., and J. B. Russell. 1996. The effect of pH on ruminal methanogenesis. FEMS Microbiol. Ecol. 20:205-210.

Van Soest, P. J., J. B. Robertson, and B. A. Lewis. 1991. Methods for dietary fiber, neutral detergent fiber, and nonstarch polysaccharides in relation to animal nutrition. J. Dairy Sci. 74:3583-3597.

Walker, N. D., A. Ameilbonne, E. Forano, F. Chaucheyras-Durand, and B. Dull. 2006. New generation probiotics: Potential enhancers of rumen function. Reprod. Nutr. Dev. 46(Suppl. 1):S120-S121. (Abstr.)

Williams, P. E., C. A. Tait, G. M. Innes, and C. J. Newbold. 1991. Effects of the inclusion of yeast culture (Saccharomyces cerevisiae plus growth medium) in the diet of dairy cows on milk yield and forage degradation and fermentation patterns in the rumen of steers. J. Anim. Sci. 69:3016-3026.

Yoon, I. K., and M. D. Stern. 1996. Effects of Saccharomyces cerevisiae and Aspergillus oryzae cultures on ruminal fermentation in dairy cows. J. Dairy Sci. 79:411-417. 